\title{
Um Estudo Teórico Sobre a Noção de Corpo: articulações com Merleau-Ponty e Francisco Varela
}

\author{
A theoretical study on body concept: \\ joints with Merleau-Ponty and Francisco Varela
}

Resumo: Este artigo é um estudo teórico sobre a noção de corpo no âmbito da filosofia e das ciências da cognição, com Maurice Merleau-Ponty e Francisco Varela. Trata-se de uma perspectiva que busca fortalecer pesquisas e práticas que lidam com o corpo numa tomada não dualista mente-corpo, eu-mundo. Com Merleau-Ponty começamos explicitando que é pela via da experiência que o autor procura fugir do dualismo mente-corpo tão instituído em nossa cultura ocidental. Depois, apresentamos o seu conceito de corpo próprio, entendido como o corpo vivido, o que o diferencia dos objetos da ciência. Na segunda parte, o problema mente-corpo será retomado a partir da perspectiva do biólogo chileno Francisco Varela, ressaltando que é a tomada de posição cartesiana que exclui o corpo do estudo da cognição. Desenvolvemos o conceito de corpo presente, que implica a concepção da mente corporificada, e não considerada abstratamente.

Palavras-Chave: Corpo. Fenomenologia. Experiência. Merleau-Ponty, Maurice. Varela, Francisco.

Abstract: This article is a theoretical study on the body concept within the philosophy and the sciences of cognition, with Maurice Merleau-Ponty and Francisco Varela. It is an approach that seeks to strengthen research and practice dealing with the body not making a dualistic mind/body I/ world. According to Merleau-Ponty the article explains that it is through experience that the author seeks to escape the mind-body dualism as established in our Western culture. Then, we present the body concept, understood as the living body, what differentiates the objects of science. In part, the mind/body problem will be resumed from the perspective of the Chilean biologist Francisco Varela, emphasizing that it is the Cartesian position taken that excludes the body of the study of cognition. We develope the concept of presente body, which involves the design of the embodied mind, and not an abstract mind.

Keywords: Body. Phenomenology. Experience. MerleauPonty, Maurice. Varela, Francisco.

POZZANA DE BARROS, Laura. Um Estudo Teórico Sobre a Noção de Corpo: articulações com Merleau-Ponty e Francisco Varela. Informática na Educação: teoria \& prática, Porto Alegre, v. 12, n. 2, p. 70-81, jul./dez. 2009.

\author{
Laura Pozzana de Barros \\ Universidade Federal do Rio de Janeiro
}

LEMBRETE Se procurar bem, você acaba encontrando Não a explicação (duvidosa) da vida, Mas a poesia (inexplicável) da vida.

Carlos Drummond de Andrade, 1984.

\section{I ntrodução}

A presentamos um estudo teórico sobre a noção de corpo no âmbito da filosofia e das ciências da cognição, com Maurice Merleau-Ponty e Francisco Varela. Buscamos com esta investigação construir ferramentas para afirmar a importância do aspecto corporal na constituição de subjetividades, entendidas como configurações processuais, singulares e coletivas. Trata-se de uma perspectiva que busca fortalecer pesquisas e práticas que lidam com o corpo numa tomada não dualista mentecorpo, eu-mundo.

A primeira parte deste trabalho será dedicada ao filósofo francês Maurice Merleau-Ponty. Neste estudo partimos explicitando que é pela via da experiência que o autor procura fugir do dualismo mente-corpo tão instituído em nossa cultura ocidental. Em seguida tratar-se-á de apresentar o seu conceito de corpo próprio, entendido como o corpo vivido, o que o diferencia dos objetos da ciência. Na segunda parte, o problema mente-corpo será retomado a partir da perspectiva do biólogo chileno Francisco 
Varela, ressaltando que é a tomada de posição cartesiana que exclui o corpo do estudo da cognição. Seguindo o pensamento de Varela, através do campo das ciências cognitivas, desenvolveremos o conceito de corpo presente, que implica uma concepção da mente corporificada, e não considerada abstratamente. No limite, pode-se dizer, de acordo com Francisco Varela, que o que move este trabalho é a crença de que "a dissociação entre mente e corpo, entre experiência e consciência, é o resultado do hábito e que os hábitos podem ser rompidos" (VARELA, 1992, p. 50).

\section{Com Merleau-Ponty}

\section{1 Algumas Considerações Acerca da Noção de Corpo}

A obra de Maurice Merleau-Ponty é de grande contribuição na abertura deste estudo pois, assim como comentou Antonio Gomes Penna (1997, p. 145), o livro Fenomenologia da Percepção “[ . . . ] representa um marco extremamente significativo na história centrada na problemática das relações entre corpo e mente". Penna refere-se aos seis capítulos dedicados nesta obra à temática do corpo como "[ . . . ] o que de mais inovador se produziu em relação a esse grande problema, com vinte e quatro séculos de história e, em especial, com os últimos quatro séculos desencadeados pela concepção cartesiana que domina o pensamento ocidental [ . . . ]" (PENNA, 1997, p. 145).

Busca-se com Merleau-Ponty uma possível reconciliação mente-corpo, visto que o autor percorre a via do meio, da experiência, escapando do pensamento dualista. Para Francisco Varela (1992), Merleau-Ponty reconhece que estamos em um mundo que, ao mesmo tempo que parece nos anteceder e ter existência independente, é inseparável de nós, e neste espaço, nesta abertura entre o eu e o mundo, entre o interno e o externo, inaugura um pensamento que percorre o entre-dois. Nesta concepção, o corpo será fonte de toda experiência possível, tendo o papel fundamental na constituição de si e do mundo. Um mundo que, segundo Merleau-Ponty (1999, p. 14), “é não aquilo que eu penso, mas aquilo que eu vivo; eu estou aberto ao mundo, comunico-me indubitavelmente com ele, mas não o possuo, ele é inesgotável".

Duas coordenadas principais atravessam este trabalho. Coordenadas estas que, por pertencerem a um mesmo plano - o plano da vida - , são muitas vezes sobrepostas e certamente inseparáveis: uma diz respeito à questão mente-corpo, que abordaremos através da noção de corpo próprio; a segunda refere-se à questão corpo-mundo, que será abordada como experiência vivida. É importante ressaltar que é pela via do entre-dois que Merleau-Ponty nos abre algumas frestas para escaparmos do pensamento dualista.

Criticando e dialogando com a filosofia de Descartes e com a psicologia que daí brota, Merleau-Ponty (1999, p. 9) afirma que "o Cogito não define a existência do sujeito pelo pensamento de existir que ele tem, não converte a certeza do mundo em certeza do pensamento do mundo e, enfim, não substitui o próprio mundo pela significação mundo". O Cogito enraíza o sujeito no mundo, o ato de pensar revela um "ser no mundo" (MERLEAU-PONTY, 1999, p. 9). Merleau-Ponty volta-se para as coisas mesmas, para um mundo anterior ao conhecimento e à análise que podemos ter dele. O conhecimento conceitual, científico, categorizado pela linguagem e pela representação, não tem lugar em sua obra como algo pré-existente. Propõe “[ . . . ] um retorno a um mundo anterior à reflexão, a volta ao irrefletido, ao mundo vivido, sobre o qual o universo da ciência é construído" (CARMO; COELHO JR., 1991, p. 45).

Para Merleau-Ponty o corpo é abertura ao mundo e um centro de ação. "O homem está no mundo, é no mundo que ele se conhece" (MERLEAU-PONTY, 1999, p. 6). E é a partir desta inserção no mundo que, diferentemente da concepção da psicologia clássica, a percepção será entendida como uma disposição ativa, "[ . . . ] o fundo sobre o qual todos os atos se destacam [ . . . ]" (MERLEAU-PONTY, 1999, p. $6)$, sendo ela, pressuposta por estes atos. "O mundo é aquilo que nós percebemos [ . . . ] e assim, [ . . . ] estamos na verdade [ . . . ]" (MERLEAU-PONTY, 1999, p. 14). Não há, assim, uma categorização de erro no ato, ou na percepção, não podemos classificar uma atuação como desviante ou desadaptada.

Há em Merleau-Ponty, como herança da Fenomenologia de Husserl, uma via de entendimento do fenômeno perceptivo que não se explica nem pelo fisicalismo, nem pelo psicologismo. O campo fenomenal, definido pela aparição dos fenômenos, distingue-se do resultado de uma análise objetivante e de algo que seria 
acessível pela via de uma introspecção. O plano da objetividade é oriundo da experiência, e por isso, segundo o autor, "é preciso que reencontremos a origem do objeto no coração de nossa experiência, que descrevamos a aparição do ser e compreendamos como paradoxalmente há, para nós, o em si" (MERLEAU-PONTY, 1999, p. 109-110). Já em seu primeiro trabalho, A Estrutura do Comportamento, buscando descrever a íntima relação entre sujeito e objeto - onde ao mesmo tempo os sujeitos estariam nos objetos e os objetos nos sujeitos, enquanto estruturas sólidas distintas das aparências - Merleau-Ponty denomina tais relações de fenômenos e chama de fenomenologia o estudo que se detém nesse tema do meio, isto é, "[ . . . ] um inventário da consciência como meio do universo [ . . . ]" (MERLEAU-PONTY, 1975, p. 232). Já no prefácio de Fenomenologia da Percepção, sua grande obra, Merleau-Ponty define a fenomenologia como um "estudo das essências situadas na existência" (MERLEAUPONTY, 1999, p. 2). Mais à frente, ela é vista como um movimento antes mesmo de ser uma teoria, e reconhece que é só em nós mesmos que a fenomenologia pode ter unidade e sentido (MERLEAU-PONTY, 1999).

É importante ressaltar que o aspecto vivido, relativo à experiência, norteia todo o estudo de Merleau-Ponty, pois antes da linguagem, da conceitualização e do aspecto formal da vida, há um viver. Enquanto consciência, enquanto sentido, não se é nada e nem se está aqui ou ali, não há distinção entre consciências. "Somos todos presenças imediatas [ . . . ] em um [ . . . ] mundo que é por definição único [ . . . ]" (MERLEAU-PONTY, 1999, p. 9). E o termo único, nesse caso, não é entendido como universal, objetivo e determinado, como também não afirma uma posição realista onde o mundo seria pré-existente. Refere-se a um mundo singular e compartilhado. Refere-se ao plano das possibilidades.

\section{2 Crítica ao Mecanicismo}

Merleau-Ponty, em Fenomenologia da Percepção, faz uma crítica à psicologia mecanicista que, visando cientificidade, coloca o corpo como um objeto entre os outros. Como ressalta a própria definição de objeto, isto seria um problema porque o corpo deveria ser entendido como um conjunto de
[ . . . ] partes extra partes e que, por conseguinte, só admitiria entre suas partes ou entre si mesmo e os outros objetos relações exteriores e mecânicas, seja no sentido estrito de um movimento recebido e transmitido, seja no sentido amplo de uma relação de função e variável (MERLEAU-PONTY, 1999, p. 111).

O organismo era visto assim, como o funcionamento de um corpo traduzido a partir da relação linear entre estímulo e receptor, cabendo “[ . . . ] aos aparelhos nervosos a potência oculta de criar as diferentes estruturas da nossa experiência [ . . . ]" (MERLEAUPONTY, 1999, p. 111) enquanto os diferentes sentidos corporais - como a visão, o tato e a audição - eram explicados diretamente pelos seus aspectos anatômicos. Comentando Merleau-Ponty, Penna nos lembra a este respeito que “o sujeito é um corpo vivo num mundo com significação intencional. Ele não é um puro sistema reativo, como o imagina o behaviorismo" (PENNA, 1997, p. 158). Merleau-Ponty (1999) utiliza-se da mudança instituída na fisiologia moderna para ressaltar que é a forma com que os estímulos se organizam entre si que determina aquilo que é sentido, e não os órgãos como meros receptores de estímulos externos. Merleau-Ponty (1999, p. 113-114) vai afirmar que "as determinações espaciais do percebido e até mesmo a presença ou ausência de uma percepção não são efeitos da situação de fato fora do organismo, mas representam a maneira pela qual ele vai ao encontro dos estímulos e pela qual se refere a eles".

Pode-se deduzir daí que para Merleau-Ponty a percepção é uma atividade, uma atividade que acontece segundo uma certa disposicão corporal: uma íntima implicação corpo-almamundo. Afirma que "a exteroceptividade exige uma enformação dos estímulos, a consciência do corpo invade o corpo, a alma se espalha em todas as suas partes" (MERLEAU-PONTY, 1999, p. 114), não há como perceber sem que aconteça qualquer movimento corporal, qualquer modificação no limite indefinido corpo-almamundo. Merleau-Ponty (1999, p. 114) coloca que "só posso compreender a função do corpo vivo realizando-a eu mesmo e na medida que sou um corpo que se levanta em direção ao mundo".

Procurando esclarecer porque essa experiência do corpo não é ela mesma uma representação, baseada na separação dualista entre o físico e o psíquico - como se o corpo pudesse ter existência independente do mundo, como 
se o pensamento pudesse estar descolado daquele que pensa, como se o afeto não fosse da ordem dos sentidos e do vivido - MerleauPonty (1999) traz para a discussão o problema que os casos de membro fantasma e anosognose nos colocam. O problema do membro fantasma diz respeito à experiência de sentir um membro que foi amputado e não se encontra mais materialmente. O problema da anosognose diz respeito à experiência de não sentir um membro que está fisicamente deficiente, porém presente; vive-se ignorando um membro que de certa forma continua fazendo parte da estrutura corporal física. Tanto a explicação psicológica quanto a fisiológica tratam de forma objetiva, sem compreender os casos senão pela explicação dual, e portanto representacional, de presença-ausência. "A vontade de ter um braço são ou a recusa do corpo doente não são formuladas por eles mesmos, a experiência do braço amputado como presente ou a do braço doente como ausente não são da ordem do 'eu penso que ...'” (MERLEAU-PONTY, 1999, p. 121). Segundo Merleau-Ponty, esses fenômenos são antes compreensíveis a partir da concepção do ser-no-mundo, onde o corpo é um veículo para que um ser vivo possa estar ligado a um determinado meio. Eles são esclarecidos através de uma visão pré-objetiva, onde o reflexo é a abertura ao sentido de uma situação - não pode ser entendido como uma mera resposta cega sem referência às circunstâncias em curso - , e a percepção uma intenção do nosso ser, um certo direcionamento no viver.

É por ser uma visão pré-objetiva que o ser no mundo [ . ] poderá realizar a junção do 'psíquico' e do 'fisiológico' (1999, p. 119). Assim, 'aquilo que em nós recusa a mutilação e a deficiência é um Eu engajado em um certo mundo físico e inter-humano, que continua a estenderse para seu mundo a despeito de deficiências ou de amputações (MERLEAU-PONTY, 1999, p. 121).

Merleau-Ponty afirma que o homem não é a simples união de um corpo a uma alma, ou vice-versa, mas o deslocamento da existência que ora se deixa ser corporal e ora se dirige aos atos pessoais. Afirma também, que os movimentos psíquicos nunca acontecem isoladamente daqueles corporais. Os fenômenos não dizem respeito à impossibilidade de compreensão da relação entre duas causalidades, a psíquica e a fisiológica, ambas implicam-se na maioria das vezes, impedindo a definição de um distúrbio mental como psíquico ou somático. Como sugere Merleau-Ponty (1999, p. 131) “a união entre a alma e o corpo [ . . .
] se realiza a cada instante no movimento da existência ".

\section{3 O Corpo Próprio}

Não é ao objeto físico que o corpo pode ser comparado, mas antes à obra de arte. (MERLEAU-PONTY, 1999, p. 208)

Quando discute a experiência do corpo próprio e a experiência do ser no mundo, MerleauPonty (1999) adverte como a psicologia mecanicista teria falhado ao pensar o corpo como objeto e não enquanto corpo vivo. Compreendendo não ser possível explicar a experiência no mundo enquanto uma evidência absolutamente física, Merleau-Ponty entende que o psicólogo criou uma segunda realidade, a psíquica, procurando dar-Ihe um estatuto científico. E para isso, assim como a ciência vigente da época, acreditou poder tratar seu objeto à distância, procurando, através da observação, descrever a experiência, distinguindo aquilo que era relativo ao objeto puro e aquilo que se referia ao observador. Procurou assim, submeter seu objeto às leis universais da ciência. A partir disto, e como consequência, "[ . . . ] a experiência do corpo se degradava em 'representação' do corpo, não era um fenômeno, era um fato psíquico" (MERLEAU-PONTY, 1999, p. 139). O objeto corpo e o seu funcionamento eram tratados de forma conceitual e abstrata, não aconteciam no mundo, não se moviam e se modificavam segundo as forças e os objetos presentes. A experiência do corpo era explicada, ora objetivamente, ora subjetivamente, mas em ambas as formas ignorava-se o tempo e aquilo que ele portava de quente, pois tudo era significado em termos representacionais e nunca realmente no plano da vida em seu puro fluir, no limite indiscernível corpo-mundo. Mesmo a subjetividade, remetida a uma instância interior, relacionava representações, onde o corpo era mais uma representação, ou no máximo, formado por uma infinidade delas. Ao lidar com representações precisamos nos lembrar que elas existem enquanto ligadas ao espaço e ao tempo. Com a concepção de corpo que Merleau-Ponty nos apresenta, podemos ousar dizer que o corpo está e é no espaço e no tempo inseparavelmente engendrados.

No diálogo com a psicologia, Merleau-Ponty (1999) se pergunta sobre a possibilidade de dar ao corpo - enquanto corpo próprio - o título de objeto, visto que antes de mais nada, o corpo 
nunca se ausentaria. Se o objeto, a princípio, é definido pela sua estrutura invariável, é preciso que sua ausência seja possível para validar sua existência. Pois, "de outra maneira ele seria verdadeiro como idéia e não presente como uma coisa" (MERLEAU-PONTY, 1999, p. 133). O meu corpo, para falar do corpo próprio, sou eu, está sempre comigo no limite do mundo que percebo, por isso não posso observá-lo à distância, como a um objeto exterior. Antes de poder percebê-lo, meu corpo é condição para que eu, simplesmente, perceba. A ação que meu corpo realiza incorpora todos os instrumentos e gestos que executa, como acontece por exemplo com um cego e sua bengala. Com o hábito e algumas necessidades físicas, a bengala passa a fazer parte da estrutura original do corpo do cego. O corpo próprio, e não o corpo dado biologicamente, "[ . . . ] é o habito primordial, aquele que condiciona todos os outros e pelo qual eles se compreendem" (MERLEAU-PONTY, 1999, p. 134). Como é para Merleau-Ponty o fato de ser impensável a ausência ou a variação do corpo próprio? Esse corpo não é definido somente por poder ser visto ou tocado, esse corpo não pode ser objeto porque é ele que possibilita que os outros objetos existam, ele está sempre presente. Como coloca o autor, a permanência do mundo só pode ser explicada pela permanência do meu corpo,

A permanência do corpo próprio, se a psicologia clássica a tivesse analisado, podia conduzi-la ao corpo não mais como objeto do mundo, mas como meio de nossa comunicação com ele, ao mundo não mais como soma de objetos determinados, mas como horizonte latente de nossa experiência, presente sem cessar, ele também, antes de todo pensamento determinante" (MERLEAUPONTY, 1999, p. 136-137)

Seguindo na exploração que a psicologia fez do corpo, Merleau-Ponty (1999) explicita, mais uma vez, que esse corpo não pode ser objeto porque ele não faz sempre uma distinção de causalidades, não distingue a princípio o ativo e o passivo. Quando, por exemplo, duas mãos se tocam, não podemos dizer que a esquerda toca e a direita é tocada, ou que ambas tocam e são tocadas como dois objetos sobrepostos. O corpo próprio nos dá duas sensações contemporaneamente, ambiguamente. Não podemos discernir, como queria a psicologia clássica, que uma mão que toca em seguida será tocada como dois objetos colocados em série no espaço. Cito: "O corpo surpreende-se a si mesmo do exterior prestes a exercer uma função de conhecimento, ele tenta tocar-se tocando, ele esboça um tipo de reflexão, e bastaria isso para distingui-lo dos objetos [ . . . ]" (MERLEAUPONTY, 1999, p. 137). Podemos entender aqui que essa reflexão não é sobre nada, não se trata de uma reflexão intelectual onde objetos e conceitos são articulados. Entendemos que a reflexão exercida pelo corpo, pode ser descrita como uma atividade de conhecimento onde o corpo se relaciona simultaneamente consigo e com o mundo - fato que não ocorre em objetos. Ao tocar e ser tocada, uma parte do corpo segue uma atividade, antes de saber nomeála ou conhecê-la. É através da ação, do fazer algo, que um fragmento do corpo exercerá uma atividade $\mathrm{x}$ ou $\mathrm{y}$, ativa ou passiva. $\mathrm{E}$, mais uma vez, é importante lembrar que de acordo com Merleau-Ponty (1999) não podemos nos referir ao corpo como um conjunto de objetos discretos. Podemos descrevê-lo segundo articulações ou dobras, mas tais demarcações serão sempre precárias e exteriores em relação à complexa função que exerce. De certa forma, antes de fazermos determinadas delimitações, devemos ressaltar que elas estão, antes de mais nada, inseridas em uma ação, fazem parte de uma atividade que as engloba e as define.

E mais, o corpo próprio é afetivo, diferentemente dos objetos externos, ele é sentido intimamente, não podemos falar de uma dor como se fala de um objeto sobre a mesa, a dor em um pé, por exemplo, não se refere ao pensamento de que meu pé está causando dor em mim, mas sim, que a dor vem do meu pé, ou meu pé tem dor. No limite, falar sobre o corpo ou pelo corpo é sempre diferente da experiência do próprio corpo. A linguagem, como se sabe, é capaz de criar, poeticamente ou não, mundos e acontecimentos infinitos, enquanto no corpo, afetivamente considerado, acontecem movimentos muito específicos e referenciados, mesmo que não nomeados. Antes de podermos dizer que estamos tristes ou emocionados, muitas vezes chora-se. E mais, chora-se muitas vezes sem a mínima certeza das possíveis causas. Por estar e ser no mundo enquanto um corpo que se orienta através do viver, o corpo próprio é fundamentalmente afetivo. É por isso que independente dos conceitos e da capacidade de abstração, um corpo pode viver e criar diferentes formas de vida. Quando buscamos saber o que é o corpo próprio, é preciso não esquecer e mesmo ressaltar que, se aqui o tratamos conceitualmente, ele só pode sê-lo, enquanto situado em um mun- 
do, espaço-temporalmente, pois ele não existe somente enquanto idéia. A meu ver, isto é uma conclusão que podemos retirar dos textos de Maurice Merleau-Ponty.

O corpo próprio é “[ . . . ] um nó de significações vivas e não a lei de um certo número de termos co-variantes [ . . . ]" (MERLEAU-PONTY, 1999, p. 206). Daí, ele poder ser aproximado mais à obra de arte do que aos objetos físicos. O corpo é formado e atravessado pela vida, sempre pulsante e inventiva. O corpo próprio não é dado e nem possui limites que de alguma maneira não possam ser ultrapassados. O corpo, assim como o mundo e o tempo, comporta abertura e múltiplas possibilidades. Ele é o portador da história vivida, é material de transporte ao mesmo tempo em que é potencial de transformação da vida que vive e é compartilhada pelos seres-no-mundo.

Segundo observou Penna,

[...] permanece havendo, tal como Nietzsche o percebera, muito mais no corpo do que conseguimos vivenciar através de nossa mente. Precisamente por este aspecto é que as análises centradas na fenomenologia do corpo próprio se mostram intermináveis [...] (PENNA, 1997, p. 156).

Ao mesmo tempo que o hábito motor é, para Merleau-Ponty (1999), a extensão de uma existência, de um ser no mundo, o hábito perceptivo pode ser descrito como a aquisição de um mundo, a forma como este ser apreende um mundo e sua significação. Ação e percepção são movimentos da existência que se realizam pelo corpo. É o olhar, não o olho e não o espírito, que vê o mundo no mesmo ato que o constrói para si. Cito: “Aprender a ver as coisas é adquirir um certo estilo de visão, um novo uso do corpo próprio, é enriquecer e reorganizar o esquema corporal" (MERLEAU-PONTY, 1999, p. 212).

\section{Com Francisco Varela}

NINGUÉM

Falar a partir de ninguém faz comunhão com as árvores Faz comunhão com as aves Faz comunhão com as chuvas Falar a partir de ninguém faz comunhão com os rios, com os ventos, com o sol, com os sapos.

Falar a partir de ninguém Faz comunhão com borra

Faz comunhão com os seres que incidem por andrajos. Falar a partir de ninguém Ensina a ver o sexo das nuvens E ensina o sentido sonoro das palavras. Falar a partir de ninguém

Faz comunhão com o começo do verbo. Manuel de Barros, 2000

\section{da Experiência Humana}

Consideramos que Francisco Varela é de extrema importância na investigação do tema referente ao corpo porque, inserido no campo das ciências cognitivas, este autor explora a experiência humana situada nas diferentes configurações da vida cotidiana. Trabalhando com a ciência, sua preocupação é antes de tudo ética onde podemos notar a grande atenção dada a dignidade da vida humana. Varela (2003) explicita claramente que seu trabalho foi inspirado e guiado pelos escritos de Merleau-Ponty. Como biólogo, seu trabalho nos interessa por apresentar uma concepção do corpo que ultrapassa o corpo biológico e natural. Seguindo o pensamento de Merleau-Ponty, Varela (2003) indica que a cultura científica ocidental requer que vejamos nossos corpos tanto como estruturas físicas quanto como estruturas experienciais vividas, como algo que é tanto 'externo' quanto 'interno', tanto biológico quanto fenomenológico. Podemos observar, assim como entende Merleau-Ponty, que para Varela (2003) a incorporação do conhecimento inclui tanto o corpo quanto a experiência. É nessa fronteira permeável entre o corpo e o mundo que nos interessa seguir investigando com Varela. Assim, seguimos nosso estudo buscando considerar a experiência do ser no mundo escapando do problema dualista mente-corpo, pois a mente em Varela ganha importância enquanto corporeidade.

No livro De Cuerpo Presente, especialmente no capítulo II, intitulado O que significa 'experiência humana'?, Francisco Varela nos fornece o solo para semearmos o presente capítulo. Varela (1992, p. 53) afirma “[ . . . ] que a conclusão cartesiana de que somos coisas pensantes era produto de sua pergunta e produto de práticas específicas, próprias de uma reflexão desincorporada e de uma 'ausência' de atenção". Descartes formulava uma pergunta, no máximo sobre o corpo, e não a partir do corpo. Como sugere Varela, ao investigar a mente, é preciso questionar tanto a idéia de que o mundo nos seja todo dado quanto a noção de que conhecer seja representar. O conhecimento por representação admite desde o início a separação entre sujeito e objeto como fundamentos dados e prévios ao procedimento de conhecer. Varela (1992) escapa desta forma de realismo, pois para ele, como podemos notar, o mundo não é independente e exterior 
a nós, ele é inseparável da estrutura que nos permite conhecê-lo.

Mais adiante, neste mesmo livro, seguindo Richard Bernstein, Varela (1992) traz à cena o termo angústia cartesiana para referir-se ao dilema que é estar entre o conhecimento que parte de fundamentos fixos e estáveis, e o conhecimento que pressupõe a ausência destes. Este último é geralmente vivido como obscuridade, caos, confusão e falta de base. Em suas palavras, "esta sensação de angústia nasce do afã por um fundamento absoluto" (VARELA, 1992, p. 169) e "quando partimos em busca de outros modos de pensamento, a angústia cartesiana nos persegue a cada passo" (VARELA, 1992, p. 170). Para Varela, a falta de fundamento com a qual a experiência humana se defronta no curso do viver, revela a cognição inserida no senso comum, pois a cognição, através dos atos que executa, é modelada e abre espaços em um mundo que não é fixo nem pré-determinado. O senso comum neste caso não é um conhecimento marcado pelo erro e pela ilusão. Como pontua Virgínia Kastrup (2001, p. 154), “é um saber-fazer corporificado, que encontra raízes na experiência individual, na tradição biológica e histórica [ . . . ], ou melhor, [ . . . ] é um plano de sentido corporal e coletivo [ . . . ]" (KASTRUP, 2001, p. 154). Daí entendemos meIhor a possibilidade de Varela (1992, p. 173) poder afirmar que "a maior aptidão da cognição humana é a capacidade de expor, dentro de amplas restrições, os problemas relevantes que se deve encarar a cada momento". Tais, problemas só podem ser enunciados e criados a partir do sentido comum, a partir da experiência corporificada e compartilhada.

Logo, podemos notar que no intuito de discutir o que pode ser a experiência humana, Francisco Varela (1992) aponta Merleau-Ponty como um pensador fundamental em nossa tradição ocidental, porque parece ser um dos únicos voltados para uma exploração entre a ciência e a experiência (o fundamental entre-dois), ou melhor, entre a experiência e o mundo.

Merleau-Ponty baseia seu trabalho em Edmund Husserl, filósofo alemão que inaugura a fenomenologia ao fazer um exame radical da experiência. Desde Descartes, a mente era vista como consciência subjetiva que deveria conter idéias claras e distintas, correspondentes ou não ao mundo. Essa era uma visão representacional da mente em sua relação com o mundo, que culminaria na noção de intencionalidade de
Franz Brentano. A consciência definia-se pela direção que apresentava, isto é, pela intencionalidade, pelo fato de ser sempre consciência de algo. Husserl, aluno de Brentano, procurou desenvolver um procedimento específico para examinar a estrutura da intencionalidade, considerada a estrutura da própria experiência. Para isto, propôs o método de redução que consistia em colocar entre parênteses, colocar de lado, os juízos comuns da relação com o mundo. A atitude comum foi chamada de atitude natural, aquela geralmente denominada de realismo ingênuo. Husserl tentava reduzir a experiência às estruturas essenciais, sustentando a idéia de que a cognição não pode ser compreendida se tomamos o mundo ingenuamente, pois é preciso considerar que o mundo leva a marca de nossas estruturas. Advertia em seguida que "[ . . . ] essa estrutura era algo que ele estava conhecendo com sua própria mente" (VARELA, 1992, p. 40).

Para Varela (1992), o problema presente na formulação husserliana é que ali ele sustentava estar dirigindo a filosofia para um enfrentamento direto com a experiência, porém ignorava o aspecto consensual e o aspecto corpóreo direto da experiência. Husserl direcionava-se à experiência e às coisas mesmas de forma meramente teórica, carecendo totalmente de uma dimensão pragmática. Por tal motivo não pôde superar a distância entre ciência e experiência, posto que a ciência, ao contrário da reflexão fenomenológica, transcende à teoria. Assim, para Varela (1992), a obra de Husserl se insere, claramente, na tradição da filosofia ocidental.

Varela (1992) valoriza mais o trabalho de Merleau-Ponty do que aquele de Husserl. Explicita que Heidegger, com a fenomenologia da existência, e Merleau-Ponty, com a fenomenologia da experiência vivida, incluem o contexto pragmático e corpóreo da experiência humana, porém ainda pecam quando o fazem de modo puramente teórico (VARELA, 1992).

Para Varela, Merleau-Ponty procura apreender nossa experiência não reflexiva, imediata, admitindo que qualquer teorização será sempre post factum, um discurso sobre a experiência que perde, necessariamente, a riqueza do viver. Merleau-Ponty critica a ciência e a fenomenologia no que tange a operação meramente conceitual sobre o indivíduo e o mundo, e afirma que precisamos de um novo método. Buscando romper com o pensamento dominante do início da década de 80 , como é exemplo 
o cognitivismo computacional que fundamentava o conhecimento principalmente a partir da informação recebida por um organismo proveniente do meio - input/output -, Varela faz a princípio uma espécie de inversão topográfica. Dá primazia ao interior, ao organismo, e não ao exterior, ao meio, dizendo que a autonomia do vivo vem "[ . . . ] da recursividade de todo o sistema em sua própria organização [ . . . ]" (COSTA, 1993, p. 81). Em seguida pontua que o problema não diz respeito mais à localização dominante do interior em relação ao exterior, ou vice-versa. A questão principal seria a de conceitualizar a mútua interdependência do dentro e do fora, do organismo e do meio. Essa mudança de problemática é nomeada por Varela como questão topológica, designada como enação. A designação de enação diz respeito justamente à

[ . . ] uma concepção, uma conceitualização de um sistema cognitivo que nem depende de uma informação que se recebe nem de uma construção unilateral de um sistema cognitivo sobre um ambiente sem estrutura, mas o que se encontra é uma permanente e inseparáve dialética entre as duas coisas (COSTA, 1993, p. 82).

Pergunta-se então: onde buscar uma tradição que contemple um exame da experiência humana no aspecto reflexivo e na vida imediata? I nfluenciado pela tradição oriental, pelo pensamento budista, Varela vai tomar como chave de trabalho o conceito de não-fundamento, a ausência de um ponto de ancoragem e partida para o conhecimento, seja ele dentro ou fora, do sujeito ou do mundo (COSTA, 1993). Varela (1992) vai se valer da prática de meditação budista de presença plena/consciência aberta, como um método para examinar a experiência, pois tal prática busca a possibilidade de estar presente com a própria mente, de alcançar um estado de alerta, experimentando o que faz a mente enquanto o alcança. Em seguida, Varela aponta que a atitude abstrata atribuída à ciência e à filosofia é simplesmente uma atitude em que o homem não está alerta, onde ele está geralmente adormecido pela atitude mecanicizada, revestida pelos hábitos, defesas e pré-conceitos que o distanciam de sua própria experiência.

A presença plena/consciência aberta, segundo Varela (1992), poderia ser desenvolvida assim como a aprendizagem. Tal desenvolvimento fortaleceria a própria presença, sendo também considerada parte da natureza básica da mente, que geralmente é obscurecida pelo hábito, mas que no fundo está sempre presente, mesmo que como possibilidade. Rompendo os hábitos e podendo experimentar a atitude de estar presente, de simplesmente estar, sem fixar-se a nada, se atingiria certa sabedoria. Porém, é importante assinalar que tal posição não corresponde à atitude de abstração e separação em relação à experiência. Como sinalizam os mestres budistas, "o conhecimento, no sentido de prajna, não é conhecimento sobre nada. Não há um conhecedor abstrato de uma experiência que está separada da experiência mesma. Os mestres budistas falam de ser um com a própria experiência" (VARELA, 1992, p. 51-52). Isto é, se a mente e o corpo não estão coordenados, no sentido budista, não estamos presentes em nossas próprias experiências.

Mais adiante Varela se interroga sobre o papel da reflexão na experiência. Há, nas palavras de Varela (1992, p. 52), uma “[ . . . ] mudança da natureza da reflexão, desde uma atividade abstrata e incorpórea até uma reflexão corpórea atenta e aberta". Por corpórea entende-se uma reflexão onde corpo e mente são unidos. Tal formulação indica que "[ . . . ] a reflexão não é sobre a experiência, e sim é uma forma de experiência em si mesma, e que essa forma reflexiva de experiência se pode realizar com a presença plena/consciência aberta" (VARELA, 1992, p. 52). Seria, assim, uma reflexão atenta e aberta. A presença plena/consciência aberta não é uma reflexão teórica sobre a experiência, nem mesmo uma ingênua impulsividade subjetiva, é sim “[ . . . ] função e expressão de nossa corporalidade" (VARELA, 1992, p. 53).

Cito:

Como em nossa cultura a reflexão está divorciada da vida corporal, o problema mente-corpo transformou-se em tema central da reflexão abstrata. O dualismo cartesiano não é uma solução e sim a formulação deste problema. Supõe-se que a reflexão é estritamente toda mental, e assim surge o problema de como está ligada com a vida corporal (VARELA, 1992, p. 55).

Para Varela (1992), o problema mentecorpo, entendido a partir da perspectiva de uma reflexão atenta e aberta, diz respeito às relações entre o corpo e a mente na experiência real, como se desenvolvem e que forma tomam. Assim coloca o filósofo japonês Yuasa Yasuo:

Só depois de assumir este terreno experiencial pode-se perguntar qual é a relação mentecorpo. O problema mente-corpo não é simplesmente uma especulação teórica, é originalmen- 
te uma experiência prática e vivida que envolve a concorrência plena da mente e do corpo. O teórico é apenas um reflexo desta experiência vivida. (YASUO, apud VARELA, 1992, p. 55)

\subsection{Corpo Presente}

No texto O Reencantamento do Concreto (2003), Varela observa que, no campo das ciências cognitivas, há em curso uma mudança paradigmática que se estende cada vez mais. Segundo palavras suas, "bem no centro desta visão emergente está a crença que as próprias unidades do conhecimento são fundamentalmente concretas, corporificadas, incorporadas, vividas" (VARELA, 2003, p. 72).

A pesquisa na área da inteligência artificial, em suas duas primeiras décadas - 1950/1970 - , entendia o conhecimento segundo uma operação por regras lógicas através da manipulação simbólica. E assim funcionam os computadores modernos. Procurando captar a inteligência dos peritos, constatou-se uma grande dificuldade operacional. Passou-se, assim, para a investigação das funções dos animais pequenos - como por exemplo, dos insetos - chegando-se, ao final de diferentes estudos, à conclusão de que é a inteligência do bebê aquela que aparenta ser a mais fundamental e profunda, aquela que adquire, por exemplo, uma língua através de expressões dispersas em um mundo previamente inespecífico.

Cientistas cognitivos integrantes da Inteligência Artificial passaram a considerar os cérebros não como máquinas lógicas, e sim como redes cooperativas, como entrelaçamentos, “[ . . . ] uma colcha de retalhos, formada por sub-redes reunidas através de um intrincado histórico remendos [ . . . ]" (VARELA, 2003, p. 73). Porém, segundo Varela, é preciso pensar, ainda, que tais sub-redes existem enquanto conectadas com um acoplamento encarnado, o sentir e o agir, que é essencial para a cognição do vivo.

A mente não seria, assim, uma entidade unificada e homogênea, e nem mesmo uma coleção de entidades, mas antes um "[ . . . ] grupo desunificado, heterogêneo, de processos" (VARELA, 2003, p. 75). A partir desta concepção de mente, definida através da emergência de diferentes sub-redes em funcionamento, Varela pergunta-se como poderia ser, então, a vida dos indivíduos sem uma compreensão baseada na unidade do sujeito. E afirma, em seguida, que "apresentamos uma prontidão-para-ação adequada para cada situação específica vivida" (VARELA, 2003, p. 76) e, entre uma ação e outra, experimentamos microperturbações continuamente. Tais prontidões-para-ação são nomeadas por Varela de 'microidentidades', e estas, em relação às situações encontradas, constituem 'micromundos', ambos entendidos como construções. "A maneira como nos mostramos é indissociável da forma pela qual as coisas e os outros se apresentam para nós" (VARELA, 2003, p. 77).

Segundo Varela (2003), tanto os humanos quanto os animais, encontraríam-se a todo momento frente à breakdowns. Os breakdowns são momentos de desestabilização do comportamento, de quebra, rachadura, bifurcação e invenção de problemas. Frente a um problema os seres vivos agem segundo a composição do presente, não sendo possível realizar decisões planejadas previamente ou exteriores à situação presente. O sucesso de uma ação se dá pela capacidade de atuar segundo a configuração de um determinado problema. Trata-se aqui da emergência do senso comum, de um saber fazer, de um saber lidar com algo em um momento específico, em um presente imediato. Algo que é “[ . . . ] examinado, então, numa micro escala: no momento durante o qual ocorre um colapso ele realiza o nascimento do concreto" (VARELA, 2003, p. 78).

O termo corporificado é tomado por Varela na pontuação de que: 1) a cognição depende de um corpo com diversas capacidades sensório-motoras; 2) tais capacidades são atreladas ao contexto biológico e cultural. Buscando explorar a especificidade do corpo na cognição do vivo, enraizando a cognição no concreto, Varela formula a noção, já citada anteriormente, de enação. Assim como bem elucidou Virgínia Kastrup (2001, p. 132), “a enação é um tipo de ação guiada por processos sensoriais locais, e não pela percepção de objetos ou formas [ . . . ], é relacionada a uma [ . . . ] cognição corporificada, encarnada, distinta da cognição entendida como processo mental. É tributária da ação, resultante de experiências que não se inscrevem na mente, mas no corpo [ . . . ]" (KASTRUP, 2001, p. 132). Varela enfatiza assim, tanto os processos sensoriais e motores, como os de percepção e ação, não simplesmente relacionados às contingências dos indivíduos, mas também aos seus respectivos meios históricos culturais. 
Dois princípios são fundamentais para que possamos entender a abordagem enativa da cognição. Primeiro: a percepção é uma ação perceptivamente guiada. Segundo Varela (2003, p. 79): “[ . . . ] as estruturas cognitivas surgem a partir de padrões sensório-motores recorrentes que permitem que a ação seja perceptivamente orientada". A noção de ação perceptivamente guiada difere radicalmente da concepção sustentada pela tradição computacional dominante, em que o perceber é definido abstratamente. Como guiar-se em situações locais? Como a percepção está ligada ao local e os locais mudam segundo a atividade do observador, aquilo que costuma ser previamente dado e independente daquele que percebe perde importância em comparação com a estrutura sensório-motora do agente cognitivo, que é a maneira pela qual o sistema nervoso liga superfícies sensoriais e motoras.

Assim, é a corporificação daquele que percebe, a sua corporeidade e não um mundo abstrato, prévio, que determina como pode ser uma determinada ação. Varela dá um enfoque à percepção, de onde podemos entender que “[ . . . ] a realidade não é projetada como algo dado; ela é dependente do sujeito da percepção, não porque ele a 'constrói' por um capricho, mas porque o que se considera um mundo relevante é inseparável da estrutura do percipiente" (VARELA, 2003, p. 79). Quanto ao entendimento do processo de percepção, Varela tece elogios à concepção desenvolvida por Merleau-Ponty e destaca o que considera como "um dos insights centrais" de sua análise fenomenológica. Cito:

Como observa Merleau-Ponty, o organismo simultaneamente instrui e é modelado pelo ambiente: M.-Ponty admitiu claramente que devemos ver o organismo e o ambiente como enlaçados em especificação e seleção recíprocas - uma questão da qual necessitamos nos recordar constantemente, pois ela é bastante contrária às visões herdadas, oriundas da tradição cartesiana (VARELA, 2003, p. 81).

É importante considerar o ser-no-mundo e o mundo-para-mim resistindo à grande tentação de generalização, onde o ser e o mundo são tomados de maneira abstrata e destacada da experiência em si. Nem idealismo nem realismo.

Como pode a emergência de micromundos ser derivada da desordem de muitos agentes cognitivos e de subredes? Varela responde brevemente que há uma abertura durante um breakdown onde uma rica dinâmica envolve subidentidades concorrentes e agentes. Nessa dinâmica, uma subrede cognitiva predomina e modula o comportamento para o momento seguinte. Tal predominância se assemelha a uma bifurcação, ou a uma forma de quebra de simetria da dinâmica caótica, e só pode acontecer enquanto vivido, enquanto presente, não enquanto planejamento.

Procurando afastar-se do abstrato, para abordar o aspecto da experiência na cognição, Varela apresenta a idéia de estruturas cognitivas corporificadas com referência a George Lakoff e Mark Johnson. Segundo tais autores

[ . . . ] as estruturas conceituais significativas originamse de duas fontes: da natureza estruturada da experiência corpórea e da nossa capacidade de projetar imaginativamente, desde certos aspectos bem-estruturados da experiência corpórea e interativa até estruturas conceituais (LAKOFF; LAKOFF apud VARELA, 2003, p. 84).

Para Varela (2003, p. 84), “[ . . . ] estruturas corporificadas (sensório-motoras) constituem a essência da experiência e estas estruturas experienciais 'motivam' a compreensão conceitual e o pensamento racional". A questão não seria afirmar a determinação conceitual e do pensamento a partir da experiência, mas sim, que “[ . . . ] a experiência possibilita e ao mesmo tempo restringe a compreensão conceitual por entre os múltiplos domínios cognitivos" (VARELA, 2003, p. 85).

Assim, afirmamos com Varela (2003) que o conhecimento não é da ordem da representação, e sim da ação, de uma ação corporificada, que, conseqüentemente, por estar de corpo presente, dá ao agir a potencialidade de conhecer. O mundo que conhecemos não é previamente dado, ele emerge em nossa história de acoplamentos. As dobras temporais que articulam enações são a origem tanto do senso comum quanto da criação na cognição. Trata-se de domínios cognitivos necessariamente presentificados e compartilhados. O conhecimento aparece cada vez mais como criação a partir de pequenos domínios, que são micromundos e microidentidades. $E$, tais "micromundos não são coerentes ou integrados [ . . . ]", a obra

[ . . . ] é mais como uma interação conversacional desregrada: a própria presença deste desregramento permite que um momento cognitivo passe a existir de acordo com a constituição e a história do sistema [ . . . ] O que tradicionalmente chamamos de 'irracional' e 'não consciente', não contradiz o que parece racional e intencional: constitui sua própria fundamentação (VARELA, 2003, p.86). 
Para finalizar gostaríamos de destacar que falando numa entrevista a Rogério da Costa sobre a concepção de corpo vivido tal como formulado por Merleau-Ponty, Varela assinala que tal concepção é, até então, estritamente um fenômeno humano e a partir da introdução da questão topológica - referente à enação, à emergência no limite entre corpo e mundo, onde não se faz mais relevância ao interno ou ao externo, - deveríamos tratar o corpo vivido enquanto um fenômeno da vida e não do homem. Para Varela (1993, p. 87), “[ . . . ] o fenômeno cognitivo e o fenômeno da vida são inseparáveis, pois desde o começo da vida ceIular, do fenômeno autopoiético, vida e conhecimento são duas coisas inseparáveis [ . . . ]". Fazendo uma certa crítica, pontuando limites da fenomenologia, Varela afirma ainda que, ocorrem fenômenos no corpo - como é exemplo a questão da imunidade corporal que não será desenvolvida aqui -
[ ... ] que abrem um nível de saber e de ser que é próprio ao corpo e que não é portanto menos fundamental para a experiência de um indivíduo, não correspondendo tampouco à topologia consciente/inconsciente. Ou seja, há raízes corporais, raízes na corporeidade, uma cognição do corpo, por assim dizer, que me parece ser um tema que a fenomenologia abandonou ou nunca esteve interessada [ . . . ] (VARELA, 1993, p. 87, grifo do autor).

Por último Varela elogia Merleau-Ponty por ter sido o único a pontuar esse espaço entredois, problema claro e fundamental que situa a cognição entre o corpo e o mundo. Mas em seguida, Varela adverte quanto ao problema ético da experiência humana, visto que na tradição ocidental, "[ . . . ] ainda que possamos falar desse entre-dois, não temos muitos meios de explorá-lo realmente, de fazer uma prática do sujeito, como diria Foucault, para trabalhar com isso [ . . . ]" (VARELA, 1993, p. 88). Pontua assim um problema que diz respeito às práticas, uma critica à fenomenologia por ser, fundamentalmente, uma filosofia pura sem uma pragmática em torno da experiência do vivido.

\section{Referências}

ANDRADE, C. D. Corpo. Rio de Janeiro: Ed. Record, 1984

BARROS, M. Ensaios Fotográficos. Rio de Janeiro: Record, 2000.

COELHO JR., N.; CARMO, P.S. do. Merleau-Ponty: filosofia como corpo e existência. São Paulo: Ed. Escuta, 1991.

FOUCAULT, M. O Cuidado de Si. In: FOUCAULT, M. História da Sexualidade. Rio de Janeiro: Ed. Graal, 1985. V. 3.

FOUCAULT, M. Tecnologias del yo y otros: textos afins. Barcelona: Paidós/ICE-UAB, 1988.

KASTRUP, V. A Invenção de Si e do Mundo: uma introdução do tempo e do coletivo no estudo da cognição. Campinas: Papirus, 1999.

LYOTARD, J.F. A Fenomenologia. Trad. Armindo Rodrigues. Lisboa: Ed. 70, 1954.

MERLEAU-PONTY, M. A Estrutura do Comportamento. Trad. José de Anchieta Corrêa. Belo Horizonte: Interlivros, 1975.

MERLEAU-PONTY, M. Fenomenologia da Percepção. Trad. Carlos Alberto Ribeiro de Moura. 2. ed. São Paulo: Martins Fontes, 1999.

PENNA, A.G. A Fenomenologia da Linguagem em Merleau-Ponty. In: Filosofia da Mente: introdução ao estudo crítico da psicologia. Rio de Janeiro: Imago, 1990. P.151 - 172

PENNA, A.G. A Fenomenologia do Corpo-Próprio e as Dificuldades de se Exprimi-la em Termos Verbais. In: REPENSANDO a Psicologia. Rio de Janeiro: Imago, 1997. P. 145 - 160. 
VARELA, F. A Individualidade: a autonomia do ser vivo. In: VEYNE, P.; VERNANT, J.P. et.al. Indivíduo e Poder. Lisboa: Ed. 70, 1988. P. 105 - 112.

VARELA, F.; THOMPSON, E.; ROSCH, E. De Cuerpo presente: las ciencias cognitivas y la experiencia humana. Barcelona: Gedisa, 1992

VARELA, F. Entrevista. In: COSTA, R. Limiares do Contemporâneo: entrevistas. São Paulo: Ed. Escuta, 1993. P. $77-97$.

VARELA, F. Etica y Accion. Santiago do Chile: Dolmen Ediciones/Granica, 1996.

VARELA, F. O reencantamento do concreto. In: PELBART, P. P.; COSTA, R. (Org.) Cadernos de subjetividade: o reencantamento do concreto. São Paulo: Hucitec,

2003. P. $71-86$

Recebido em agosto de 2009

Aprovado para publicação em novembro de 2009

\section{Laura Pozzana de Barros}

Doutoranda do Programa de Pós-Graduação em Psicologia da Universidade Federal do Rio de J aneiro.

E-mail: laura.pozzana@gmail.com 